\title{
Comparison of Counts of Neurons in the Locus Coeruleus Made From Serial Sections and From a Single Section at the Centre of the Nucleus
}

\author{
C.Q. Mountjoy and W. Bondareff
}

\begin{abstract}
This paper describes the comparability of counts in the locus coeruleus made from serial sections and those made from a single section at the point of greatest density of neurons. Samples of the locus coeruleus neuronal population derived from single section counts though not exactly comparable, are of comparable utility to those obtained from more laborious total neuronal counts. The simpler method was used to examine the hypothesis that there are subtypes of senile dementia of the Alzheimer type. Separation into two groups was achieved when independent variables of cortical neuronal counts and tangle estimates were used. This finding adds to the growing evidence that Alzheimer's disease of the senile type is not a unitary disorder.
\end{abstract}

RÉSUMÉ: Comparaison de numérations de neurones dans le locus coeruleus à partir de coupes sériées. Cet article décrit la possibilité de comparer des numérations cellulaires dans le locus coeruleus à partir de coupes sériées et celles faites à partir d'une coupe unique faite au point où la densité des neurones est maximale. Des échantillons de la population neuronale du locus coeruleus tirés de numérations faites sur des coupes uniques, même si elles ne sont pas comparables de façon exacte, sont d'utilité comparable à celles oubliées plus péniblement à partir de numérations neuronales totales. Cette méthode plus simple a été utilisée pour vérifier l'hypothèse qu'il existe des sous-types de démence sénile de type Alzheimer. Nous sommes parvenus à les séparer en deux groupes au moyen de variables indépendantes des numérations des neurones du cortex et d'estimés du nombre des enchevêtrements. Cette observation ajoute aux observations de plus en plus nombreuses indiquant que la maladie d'Alzheimer du type sénile n'est pas une affection unitaire.

Can. J. Neurol. Sci. 1986; 13:480-482

The nucleus locus coeruleus contains the cells of origin of the noradrenergic input to the cerebral cortex. The number of its neurons decreases with increasing age ${ }^{1}$ and are further reduced in senile dementia of the Alzheimer type. $2,3.4,5,6$ With the exception of the study of Bondareff et $\mathrm{al}^{5}$ these counts in Alzeheimer's Disease were made on slides from the centre of the nucleus rather than by counts made by serial sections. It is therefore important to determine whether the central counts are representative of the nucleus as a whole so that studies can be compared and time consuming serial counts avoided in the future. The bimodal distribution of the counts in the locus coeruleus ${ }^{5}$ has suggested a heterogeneity in senile dementia of the Alzheimer type ${ }^{7}$ as have biochemical studies. ${ }^{8}$

If a rapid method of counting cells in the locus coeruleus can be established a larger number of cases can be examined and the question of heterogeneity of Alzheimer's disease with locus count as a discriminator can be addressed.

\section{METHOD}

The thirty cases whose locus coeruleus had been counted in serial sections by means of a Quantimet Image Analysing Computer (Cambridge Instruments) and reported by Bondareff et $\mathrm{al}^{5}$ were reexamined. Slides from the centre of the nucleus were examined and the point of maximum size determined. Counts of neurons in the locus coeruleus in the section of maximum density were made by eye and the count so obtained was compared with the count obtained by counts of serial sections. The reliability of the method was determined by comparing the counts of the first observer with independent counts made by a second observer.

To examine the question of heterogeneity in Alzheimer's disease three separate discriminant function analyses using the locus count as the dependent variable were performed on twenty-five demented cases. The independent variables in these 


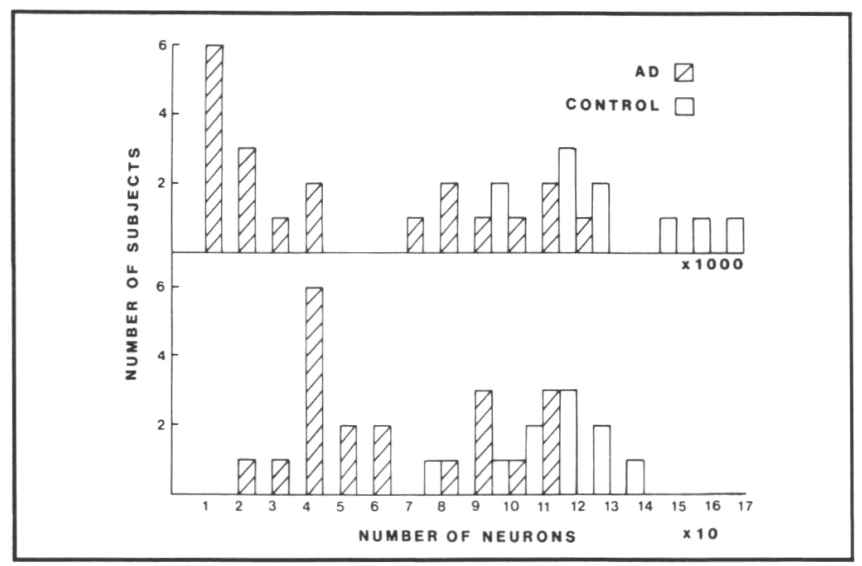

Figure l-Distributions of neuronal counts of the locus coeruleus in 20 Alzheimers disease and 10 controls. Upper histogram Quantimet assisted counts of total neuronal population. Lower histogram average neuronal counts of single representative sections at the site of maximal neuronal density. (Reproduced with permission from Neurobiology of Aging)

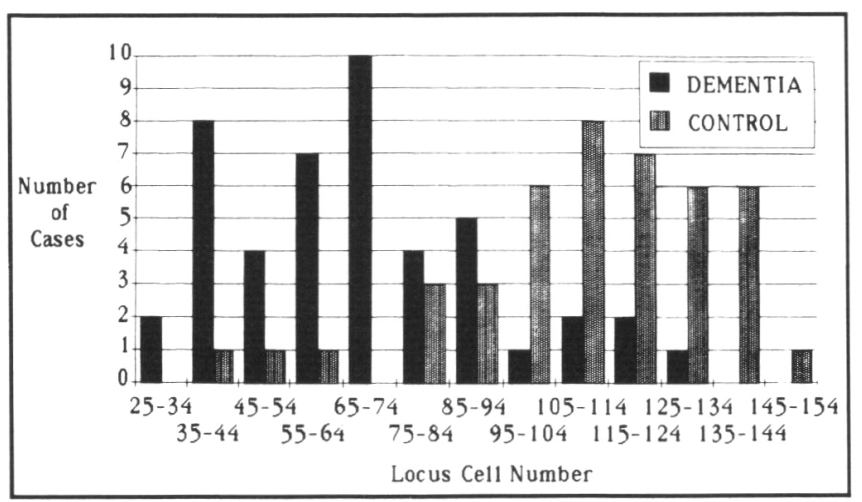

Figure 2 - Histogram of the distribution of numbers of locus coeruleus neurons plotted separately for Alzheimer patients (black) and non-demented controls (stippled). three analyses were cortical neuronal and plaque counts and tangle estimates reported by Mountjoy et al. ${ }^{9}$ The stepwise discriminant function analysis took into account the prior probabilities of a subject belonging to a particular group and the distance between groups was maximised by use of the Mahalonobis technique.

\section{Results}

There was no significant difference between the mean counts (81 s.d. 33.98; 83 s.d. 33.99$)$ made by the two observers $(\mathrm{t}=-1.29$ d.f. $29 \mathrm{p}=0.2)$ and there was a high correlation between the two sets of counts $(r=0.97 n=30 p<0.001)$.

The distributions of the counts made by serial sections and by counts from a single count are shown in Figure 1. It can be seen that the obvious discontinuity in the distribution of the counts made on serial sections is less clear, though still present, in counts made from single sections. The single counts are not therefore directly comparable with the serial section counts but they are highly correlated with each other $(r=0.91 n=30$ $p<0.001$ ) and single and serial counts have been shown to correlate with a number of other variables at comparable levels of significance. ${ }^{10}$

The single count of the locus coeruleus was used for a further sample of controls and dements giving a total of 90 cases. The distribution of the counts is shown in Figure 2. Although there is no longer a discontinuity in the distribution of the locus counts in the demented group the distribution is not normal and a group of low count dements is discernible.

The point of rarity in the distribution of whole counts of the nucleus found by Bondareff et $\mathrm{al}^{5}$ corresponded to a count from a single section of $67^{10}$ but it can be seen from Figure 2 that the dip in distribution is slightly lower than 67.

For the purposes of the discriminant function analysis the distribution of the locus counts was divided into three groups with those near 65 being regarded as "unclassified" and those below 61 or above 70 regarded as belonging to definite grouped cases. Three separate discriminant function analyses were carried out using counts for neurons and plaques and estimates of tangles as the independent variables and the locus count as the dependent variable. Similar analyses were carried out using age

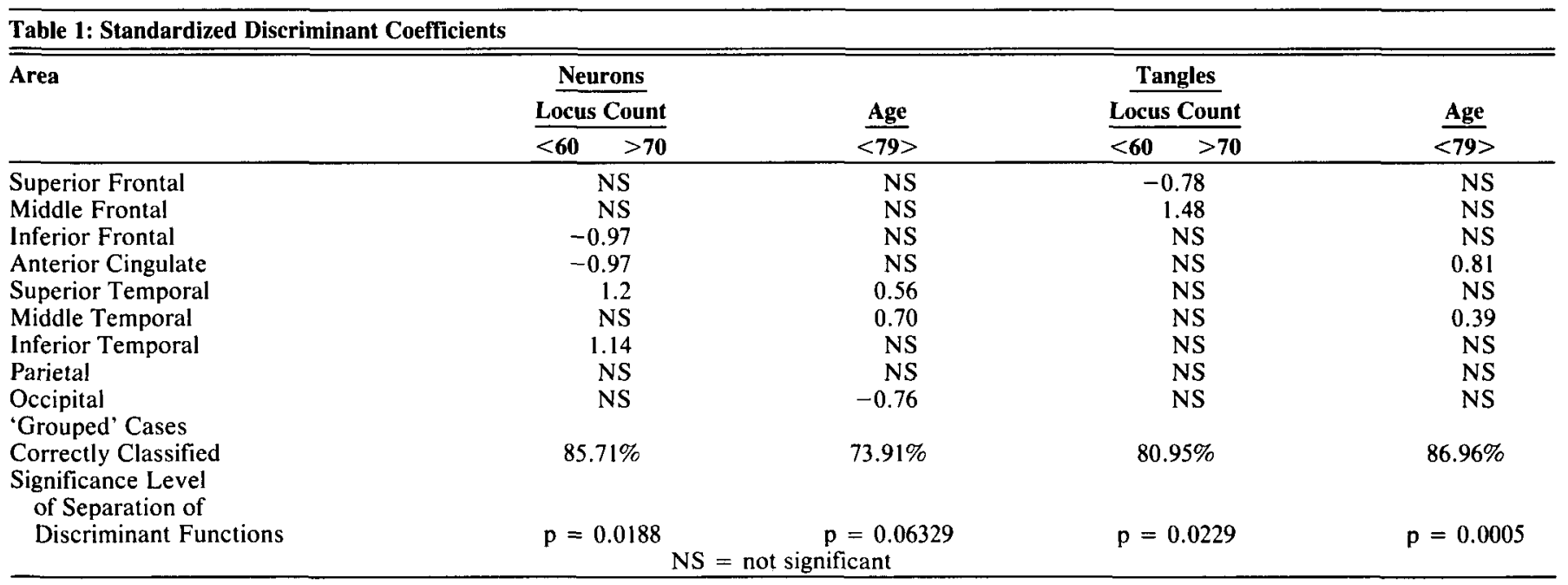


at death as the dependent variable because of the evidence that this might be a better discriminator. ${ }^{8}$

The plaque counts did not prove to be statistically significant in dividing the dements into two groups either on the basis of the locus count or the age at death. On the other hand cortical neuronal counts were significant discriminands when the locus count but not the age at death was the dependent variable. Tangle estimates proved to be better discriminands than cortical neurons and were also discriminands when age at death was the dependent variable. The results, their statistical significance and the proportion of cases correctly classified, a method of determining the relevance of the classification, are shown in Table 1.

\section{Discussion}

The results presented in this paper show firstly that single counts of cells of the locus coeruleus are highly correlated with total counts of the nucleus and this finding strengthens those papers which have depended on counts from a limited number of sections to adduce evidence of cell loss in Alzheimer's Disease. Secondly the method has been shown to be statistically reliable and although there were some inconsistencies on individual scores there was no statistically significant difference between the mean counts of the two observers.

The use of this simplified method of counting has allowed us to make counts in a greater number of cases than would have been possible if the single and serial counts had not corresponded so well.

We examine the hypothesis that senile dementia of the Alzheimer type can be divided into two groups on the basis of cell counts in the locus coeruleus. The discriminant function analyses reported here show that the classification can be sustained when cortical neurons and tangles, but not plaques, are used as the independent variables. The small number of variables that contribute to the discriminant function suggests that cortical neuronal counts and tangle estimates in the nine areas examined are highly intercorrelated rather than implying important anatomical differences in the disease processes. However it is interesting to note that significant discriminands in the neuronal counts are from the frontal and temporal lobes and their signs are opposite. This could be interpreted as a reflection of the different pattern of atrophy found in younger and older dements. " Such interpretations do not hold up in the other analyses. Separation into two groups also occurs when the locus count is used as the dependent variable and cortical biochemical measures are the independent variables ${ }^{12}$ though better separation is achieved when age at death is the dependent variable. These findings cannot be explained by the duration or severity of the dementia because their entry as variables in the discriminant function analyses shows that they make no contribution to the separation of the two groups.

The results reported here show the utility of the locus count and add to the growing body of evidence that suggests that Alzheimers disease is not a single entity.

\section{REFERENCES}

1. Vijayashankar $\mathrm{N}$ and Brody $\mathrm{H}$. A quantitative study of the pigmented neurons in the nucleus locus ceruleus and subcoeruleus in man as related to aging. J Neuropath and Exper Neurol 1979; 38: $490-497$.

2. Forno LS. The locus caeruleus in Alzheimer's disease. J Neuropath Exper Neurol 1978; 37: 614.

3. Tomlinson BE, Irving D, Blessed G. Cell loss in the locus coeruleus in senile dementia of the Alzheimer type. J Neurol Sci 1981; 49: 419-428.

4. Mann DMA, Yates PO, Hawkes J. The noradrenergic system in Alzheimer and multi-infarct dementias. J Neurol Neurosurg Psychiatry 1982; 45: 113-119.

5. Bondareff W, Mountjoy CQ, Roth M. Loss of neurons of origin of the adrenergic projection to cerebral cortex (nucleus locus ceruleus) in senile dementia. Neurology 1982; 32: 164-168.

6. Iversen LL, Rossor MN, Reynolds GP et al. Loss of pigmented dopamine-b-hydroxylase positive cells from locus coeruleus in senile dementia of Alzheimer's type. Neurosci Letters 1983; 39: 95. 100.

7. Bondareff W. Age and Alzheimer's disease. Lancet 1983; 1: 1447.

8. Rossor MN, lversen LL, Reynolds GP, et al. Neurochemical characteristics of early and late onset types of Alzheimer's disease. Br Med J 288: 961-964.

9. Mountjoy CQ, Roth M, Evans NJR, et al. Cortical neuronal counts in normal elderly controls and demented patients. Neurobiol Aging. 1983; 4: 1-11.

10. Bondareff W, Mountjoy CQ. Number of neurons in nucleus locus ceruleus in demented and non-demented patients: rapid estimation and correlated parameters. Neurobiol Aging 1986 (in press).

11. Hubbard BM. Anderson JM. A quantitative study of cerebral atrophy in old age and senile dementia. J Neurol Sci 1981; 50: 135-145.

12. Bondareff W, Mountjoy CQ, Roth M, et al. Age and histopathological heterogeneity in Alzheimer's Disease: evidence for subtypes. Arch Gen Psychiatry (in press). 